\title{
Oestrogen Replacement Therapy for Prevention of Osteoporosis after Oophorectomy
}

\author{
J. M. AITKEN， D. M. HART， R. LINDSAY
}

British Medical fournal, 1973, 3, 515-518

\author{
Subjects and Methods
}

Summary

The value of oestrogen therapy in the prevention of osteoporosis after oophorectomy was assessed in 114 middle-aged women who participated in a double-blind controlled trial of mestranol in an average daily dose of $23 \mu \mathrm{g}$. The skeletal response to treatment was measured by a photon absorption technique. Where treatment was started within two months of operation subsequent bone mineral loss was prevented. Treatment started three years after oophorectomy caused a highly significant increase in bone mineral content. When treatment was delayed for six years mestranol failed to prevent subsequent bone mineral loss with age. These effects occurred independently of the associated humoral changes in calcium and phosphorus homoeostasis. Mestranol in this dosage appeared to be relatively safe, but it is too early to evaluate the long-term hazards of such therapy.

\section{Introduction}

The value of oestrogen therapy in the treatment of osteoporosis is far from clear. Ever since Albright et al. (1941) drew attention to the association between the menopause and spinal osteoporosis oestrogen therapy has enjoyed a somewhat protracted though chequered vogue in the management of osteoporosis both in women and in men (Albright, 1947).

In spite of reports of positive calcium balance induced by short-term oestrogen administration (Anderson, 1950) and a reduction in the bone resorption rate as measured with radiocalcium (Lafferty et al., 1964) and by microradiography (Riggs et al., 1969) no macroscopic radiographical evidence for an oestrogen-induced increase in bone mineral content has been published.

The poorly controlled retrospective studies of Henneman and Wallach (1957), Davis et al. (1966), and Meema and Meema (1968) indicated that oestrogen therapy given after oophorectomy may at best only delay the onset of bone mineral loss with age. Furthermore, little attention has been paid to the possible hazards of such long-continued oestrogen therapy in postmenopausal women, though Gow and MacGillivray (1971) considered them to be formidable.

In view of the lack of adequate control data furnished by previous workers studying the effects of oestrogen therapy in the treatment of postmenopausal osteoporosis we report here the results of a double-blind controlled trial of the oestrogen mestranol in the prevention of bone mineral loss with age after oophorectomy.

\footnotetext{
University Department of Medicine, Western Infirmary, Glasgow G11 6NT

J. M. AITKEN, M.B., M.R.C.P., Senior Registrar (Present appointment: Lecturer, Medical Professional Unit, St. Bartholomew's Hospital, London ECIA 7BE)

R. LINDSAY, M.B., PH.D., Lecturer

Department of Gynaecology, Stobhill General Hospital, Glasgow G21 3UW

D. M. HART, M.D., F.R.C.S., Consultant Gynaecologist
}

Altogether 147 healthy women who had undergone hysterectomy and bilateral oophorectomy for non-malignant disease two months, three years, or six years previously were reviewed. They were invited to take part in the therapeutic trial of a drug which, it was explained, might prevent the subsequent development of osteoporosis. All these women freely agreed to participate and were given either $20-\mu \mathrm{g}$ mestranol tablets or placebo tablets of similar appearance, of which they were instructed to take two daily. Further supplies of tablets were obtained by returning a coded postcard to the hospital pharmacy, and thus it was possible to make a rough estimate of the number of tablets consumed by each subject. No women were included who gave a history of hepatitis or either deep venous thrombosis or pulmonary embolism, or both, or specific diseases known to be associated with bone mineral loss. Women who had taken hormone therapy between oophorectomy and the time of review were also excluded.

Samples of venous blood and urine were obtained from each subject fasting at the start of treatment and at yearly intervals thereafter. An $x$-ray picture of the right hand was taken for densitometric and morphological measurements at the start of treatment alone, and a photon absorptiometric measurement was made at the midpoint of the third metacarpal (Shimmins et al., 1972 a) at the start of treatment and at yearly intervals thereafter.

Biochemical measurements on serum and, where appropriate, urine were made by standard procedures. Calcium was estimated by atomic absorption spectrophotometry (Trudeau and Freier, 1967). Standard AutoAnalyzer techniques were used to estimate creatinine (N 11), phosphorus (N 4), the serum aspartate (SGOT) and alanine (SGPT) transaminases (N 44), and blood sugar (N 2b). Lactic dehydrogenase was measured by the method of Wroblewski and LaDue (1955).

Urinary calcium excretion was calculated according to Nordin et al. (1967). The index of phosphorus excretion was calculated as described by Nordin and Bulusu (1968). The aluminium equivalent was measured from the hand $x$-ray picture (Anderson et al., 1966), and from this the whole bone density at the metacarpal midpoint was calculated (Shimmins et al., 1972 b). The whole bone density measurements were converted to percentile values as described previously (Aitken et al., 1973 a). The metacarpal mineral content, measured by photon absorptiometry, was standardized to allow for subjects of different size by dividing the ash per unit length by the metacarpal length to give the standardized metacarpal ash.

The statistical method used was Student's $t$ test.

Thirty-one women-16 from the mestranol group and 15 from the placebo group-failed to complete one year's treatment. One woman from the mestranol group who was hypertensive at the outset died within three months from a cerebrovascular catastrophe. All but six of the remaining defaulters were traced and found to be in good health. Two subjects had to be excluded from further assessment because their own practitioners had prescribed oestrogens. Thus 114 women completed one or more years of observation and the results from these patients are reported below.

\section{Results}

The initial bone mineral measurements in the women studied are shown in table I. The mean age of the women who started 
TABLB I-Bone Mineral Measurements before Treatment with Mestranol $(M$. TABLB I-Bone Mineral Measurements before Treatment with Mestranol $(M$. or Placebo (P.) assessed Radiographically by Whole Bone Density (W.B.D.)
Percentile and Photon Absorptiometrically by Standardized Metacarpal Percentile and Photon Absorptiometrically
Mineral (S.M.A.). Means \pm S.E. of Means

\begin{tabular}{|c|c|c|c|c|c|}
\hline & $\begin{array}{l}\text { Treat- } \\
\text { ment } \\
\text { group }\end{array}$ & $\begin{array}{l}\text { No. of } \\
\text { of } \\
\text { Women }\end{array}$ & $\begin{array}{c}\text { Age } \\
\text { (Years) }\end{array}$ & $\begin{array}{c}\text { W.B.D. } \\
\text { Percentile }\end{array}$ & $\begin{array}{l}\text { S.M.A. } \\
\text { (mg ash/ } \\
\mathbf{m m} / \mathrm{cm})\end{array}$ \\
\hline $\left.\begin{array}{l}\text { Two months post- } \\
\text { oophorectomy (group Z) } \\
\text { Three years post- } \\
\text { oophorectomy (group T) } \\
\text { Six years post- } \\
\text { oophorectomy (group S) }\end{array}\right\}$ & $\begin{array}{l}\mathbf{P} \\
\mathbf{M} \\
\mathbf{P} \\
\mathbf{M} . \\
\mathbf{P} . \\
\dot{\mathbf{M}}\end{array}$ & $\begin{array}{l}10 \\
10 \\
39 \\
41 \\
17 \\
17\end{array}$ & $\begin{array}{l}44.1 \pm 2.3 \\
45.0 \pm 0.7 \\
49.1 \pm 0.5 \\
49.1 \pm 0.6 \\
51.6 \pm 0.4 \\
50.4 \pm 1.0\end{array}$ & 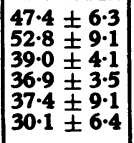 & $\begin{array}{l}7 \cdot 23 \pm 0.24 \\
7.44 \pm 0.33 \\
6.79 \pm 0 \cdot 15 \\
6.76 \pm 0.10 \\
6.64 \pm 0.23 \\
6.77 \pm 0.15\end{array}$ \\
\hline
\end{tabular}

W.B.D. = Whole bone density. S.M.A. = Standardized metacarpal ash.

treatment within two months of oophorectomy (group Z) was about four years less than that of the women who started treatment three years after oophorectomy (group $T$ ) and six years less than that of the women oophorectomized six years (group S) before treatment was started. The mean whole bone density percentile values were $50 \%$ in group $Z, 38 \%$ in group $T$, and $34 \%$ in group $S$. The standardized metacarpal ash was correspondingly highest in group $Z$ and lowest in group $S$. The mean yearly tablet consumption in the mestranol-treated women was $414 \pm 81$ in group $Z, 431 \pm 29$ in group $T$, and $418 \pm 43$ in group $S$. The means did not differ significantly and represent an average daily dose of about $23 \mu \mathrm{g}$. The mean yearly tablet consumption by the women taking the placebo was similar to that of the mestranol-treated women.

\section{BONE MINERAL CHANGES}

The mean yearly change in metacarpal mineral content during the trial is shown in fig. 1. The placebo-treated women in group $\mathrm{Z}$ experienced a mean loss of $1.77 \mathrm{mg}$ ash $/ \mathrm{mm}$, which represents a $3.9 \%$ fall in bone density, whereas the mean metacarpal mineral content fell by only $0.06 \mathrm{mg}$ ash $/ \mathrm{mm} / \mathrm{year}$, or $0.1 \%$, in the mestranol-treated women $(P<0.05)$. In group $T$ the placebo group experienced a mean metacarpal mineral loss of $0.12 \mathrm{mg}$ ash $/ \mathrm{mm} /$ year, or a fall of about $0.3 \%$, whereas the mestranol-treated women sustained a mean increase in metacarpal mineral of $0.96 \mathrm{mg} \mathrm{ash} / \mathrm{mm} / \mathrm{year}$, or $2.4 \%(\mathrm{P}<0.005)$.

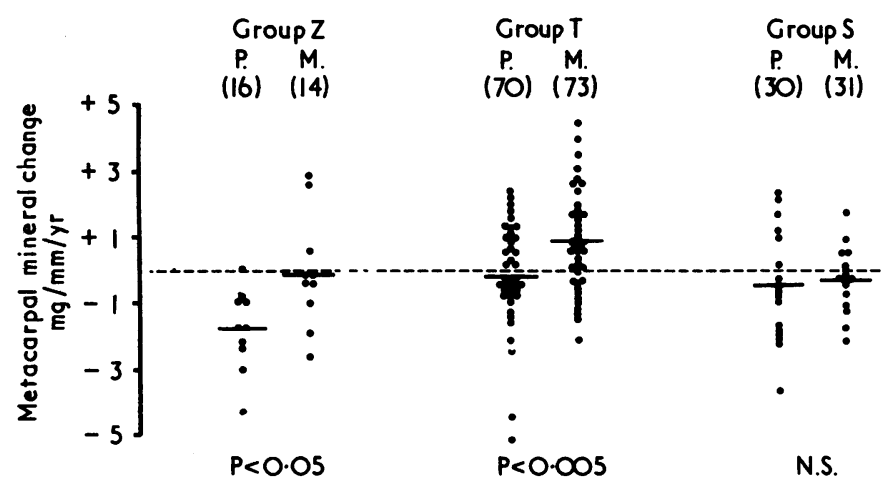

FIG. 1-Mean yearly change $n$ metacarpal mineral in women receiving mestranol (M.) or placebo (P.) starting two months (group $Z$ ), three years (group T), or six years (group S) after oophorectomy. Numbers of patienttreatment-years are given in parentheses. N.S. = Not significant.
In group $S$ both the mestranol and placebo groups lost metacarpal mineral at a rate of $0.36 \mathrm{mg}$ ash $/ \mathrm{mm} /$ year, or $0.9 \%$.

The mestranol-treated women from group $S$ were matched accurately for age with 17 mestranol-treated women from group $T$. The mean yearly change in metacarpal mineral is shown in fig. 2. The women from group $T$ were again found to sustain a significant increase in metacarpal mineral of $1.24 \mathrm{mg}$ ash $/ \mathrm{mm} /$ year, or $3.1 \%$, as compared with a fall in group $S(t=2.72$; $\mathrm{P}<0.02$ ).

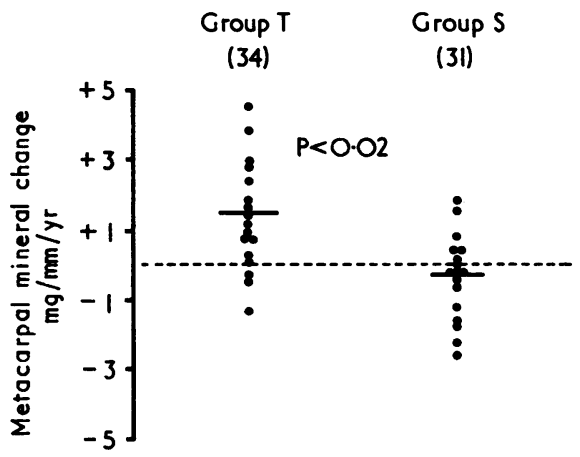

Fig. 2-Mean yearly change in metacarpal mineral in two groups of agematched women taking an average of $23 \mu \mathrm{g}$ mestranol daily, starting three years (group T) or six years (group S) after oophorectomy. Numbers of patient-treatment-years are given in parentheses.

\section{EFFECTS ON CALCIUM AND PHOSPHORUS}

The most recent measurements relating to serum and urinary calcium and phosphorus are shown in table II. All the results from the placebo-treated women were pooled and the results from the other groups were compared with this. This procedure was adopted because seasonal variations which are found in these parameters (Aitken and Lindsay, 1972) might otherwise have biased the mean values found in each placebo group, though the means did not, in fact, differ significantly from one group to another. None of the results from the mestranoltreated women from group $\mathrm{Z}$ were significantly different from the placebos, but the numbers were too few for meaningful assessment. The mean serum calcium concentrations were lower in the mestranol-treated women from groups $T$ and $S$ but this difference was significant only in group $S(P<0.01)$. The mean serum phosphorus concentrations were very significantly lower in the mestranol-treated women than they were in the pooled placebos $(P<0.001)$. Urinary calcium excretion was significantly lower $(P<0.005$ and $P<0.02)$ and relative urinary phosphorus excretion significantly higher $(P<0.001$ and $\mathrm{P}<0.01$ ) in groups $\mathrm{T}$ and $\mathrm{S}$ respectively when compared with the pooled controls.

EFFECTS ON HEPATIC FUNCTION AND CARBOHYDRATE METABOLISM No clinical evidence of hepatic dysfunction was detected. Three women, one from the mestranol group and two from the placebo group, had biochemical evidence suggestive of hepatic dysfunction, and in all instances these changes were transitory. In

TABLE II-Effect of Mestranol Therapy on Certain Humoral Criteria of Calcium and Phosphorus Metabolism. Means \pm S.E. of Means

\begin{tabular}{|c|c|c|c|c|c|}
\hline & $\begin{array}{l}\text { No. of } \\
\text { Subjects }\end{array}$ & $\begin{array}{l}\text { Serum Calcium } \\
(\mathrm{mg} / 100 \mathrm{ml})\end{array}$ & $\begin{array}{c}\text { Serum Phosphorus } \\
(\mathrm{mg} / 100 \mathrm{ml})\end{array}$ & $\begin{array}{l}\text { Ca.E. } \\
\text { (mg Ca/100 ml G.F.) }\end{array}$ & I.P.E. \\
\hline \multirow[t]{2}{*}{ 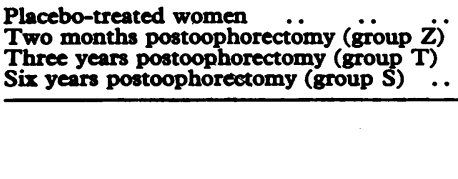 } & $\begin{array}{l}66 \\
10 \\
41 \\
17\end{array}$ & $\begin{array}{l}9 \cdot 75 \pm 0.04 \\
9 \cdot 60 \pm 0.13^{*} \\
9 \cdot 63 \pm 0.05 t \\
9.47 \pm 0.06 \ddagger\end{array}$ & $\begin{array}{l}3.56 \pm 0.05 \\
3.25 \pm 0.21 * \\
3.08 \pm 0.07 \dagger \\
3.12 \pm 0.14 \ddagger\end{array}$ & $\begin{array}{l}0.098 \pm 0.007 \\
0.090 \pm 0.020 * \\
0.064 \pm 0.007 \dagger \\
0.064 \pm 0.007 \ddagger\end{array}$ & $\begin{array}{l}-0.122 \pm 0.037 \\
-0.040 \pm 0.103 * \\
+0.086 \pm 0.043+ \\
+0.095 \pm 0.058 \neq\end{array}$ \\
\hline & & $\begin{array}{r}{ }^{*} t=1.22 ; \\
t t=1.68 ; \mathrm{N} . S . S \\
\ddagger t=3.06 ; \mathrm{P}<0.01\end{array}$ & $\begin{array}{c}{ }^{*} t=1.94 ; \mathrm{N} . \mathrm{S} . \\
+t=5.55 ; \mathrm{P}<0.001 \\
\ddagger t=3.47 ; \mathrm{P}<0.001\end{array}$ & $\begin{aligned} * t & =0.50 ; N . S . \\
t t & =3.26 ; \mathrm{P}<0.005 \\
\ddagger t & =2.43 ; \mathrm{P}<0.02\end{aligned}$ & $\begin{aligned} & * t=0.74 ; \mathrm{N} . S . \\
& t t=3.62 ; \mathrm{P}<0.001 \\
& \neq t=2.80 ; \mathrm{P}<0.01\end{aligned}$ \\
\hline
\end{tabular}

N.S. = Not significant. G.F. = Glomerular filtrate. Ca.E. = Calcium excretion. I.P.E. $=$ Index of phosphorus excretion. 
each instance both the SGOT and SGPT concentrations in the serum were raised, with the SGPT value being about double that of SGOT. With these exceptions all transaminase values were under 50 Frankel $\mathrm{U} / \mathrm{ml}$, and the mean values for the mestranol and placebo groups are shown in table III. Serum lactic dehydrogenase concentrations were all under $230 \mathrm{mU} / \mathrm{ml}$ but the mean value in the mestranol-treated group was significantly lower than that found in the placebo group $(P<0.01)$.

TABLE III-Effect of Prolonged Treatment with Mestranol or Placebo on Liver Function and Carbohydrate Metabolism. Means \pm S.E. of Means

\begin{tabular}{l|c|c|c|c}
\hline & $\begin{array}{c}\text { SGOT } \\
\text { (Frankel } \\
\text { U/ml) }\end{array}$ & $\begin{array}{c}\text { SGPT } \\
\text { (Frankel } \\
\text { U/ml) }\end{array}$ & $\begin{array}{c}\text { Serum Lactic } \\
\text { Dehydrogenase } \\
(\mathrm{mU} / \mathrm{ml})\end{array}$ & $\begin{array}{c}\text { Blood Sugar } \\
(\mathrm{mg} / 100 \mathrm{ml})\end{array}$ \\
\hline $\begin{array}{l}\text { Mestranol } \\
\text { Placebo }\end{array}$ & $\begin{array}{c}19.3 \pm 1.3 \\
21.5\end{array}$ & $\begin{array}{c}21.0 \pm 1.6 \\
19.7 \pm 1.3\end{array}$ & $\begin{array}{c}164.2 \pm 6.5 \\
189.6 \pm 6.5\end{array}$ & $\begin{array}{c}74.9 \pm 1.0 \\
77.8 \pm 0.9\end{array}$ \\
\hline & $t=1.42 ;$ N.S. & $t=0.65 ;$ N.S. & $t=2.71 ; \mathrm{P}<0.01$ & $t=2.12 ; \mathrm{P}<0.05$ \\
\hline
\end{tabular}

The fasting blood sugar concentrations were all under $100 \mathrm{mg} /$ $100 \mathrm{ml}$, with the exception of one woman in the mestranoltreated group who developed frank diabetes mellitus. This subject had a normal blood sugar concentration at the start of therapy but she had a strong family history of diabetes, with both parents and a cousin suffering from the disease, and had conceived two infants weighing more than $10 \mathrm{lb}(4,535 \mathrm{~g})$ at birth. The mean blood sugar concentrations in the other women are shown in table III, and it is seen that the mestranol-treated women had a significantly lower concentration than that found in the placebo group $(P<0 \cdot 05)$.

\section{ASSOCIATED REACTIONS}

During the period of observation of the 114 women who completed one or more years of treatment there was only one side effect which appeared relatively commonly in the mestranoltreated women-namely, cramps in the calves and feet when in bed at night. Three further "vascular" complications were found in the mestranol-treated women. One woman who had a history of recurrent superficial thrombophlebitis had a further episode of this condition. She continued therapy and made a satisfactory recovery. Another woman experienced an episode of palpitation associated with prolonged chest pain for which she was treated at home, but subsequently she was not found to have cardiographic evidence of myocardial infarction. Treatment was not discontinued and she made an uneventful recovery. Another woman, who was hypertensive at the outset, had a transient hemiparesis from which she made a complete recovery in spite of continuing therapy. One woman from the placebo group was found to have myeloid leukaemia after two years in the trial and she died one year later.

\section{FRACTURES}

None of the mestranol-treated women sustained fractures, but two women from the placebo group fractured bones-one Colles's fracture and one fracture of the lateral malleolus.

\section{Discussion}

It has been shown that within two years of oophorectomy there was a significant loss of metacarpal mineral and that these skeletal changes could largely be prevented by the administration of a small daily dose of the oestrogen mestranol. These observations are in agreement with the findings of Meema et al. (1965), Davis et al. (1966), Meema and Meema (1968), Nordin et al. (1968), and Aitken et al. (1973 a). We have also shown that when mestranol therapy in a similar dosage was delayed for three years from the time of oophorectomy a highly significant increase in metacarpal mineral content was obtained. Such an increase in skeletal mass after oestrogen therapy has not been reported previously. Finally, it was established that delaying oestrogen replacement for more than six years after oophorectomy precluded a significant osteotrophic response to treatment. The osteotrophic response to mestranol did not appear to be age-related, nor was it due to differences in dosage. The importance of this time interval between the oophorectomy and the start of oestrogen therapy may well explain the indifferent results of Riggs et al. (1969), who studied the skeletal effects of large doses of oestrogens on women roughly 13 years postmenopausal. Similarly the poor response to high-dose mestranol therapy which was observed in oophorectomized adult rats (Aitken et al., 1972) may well be explained by the long delay between onphorectomy and oestrogen replacement.

Previous workers have used a number of different skeletal sites for assessing bone mineral changes after oophorectomy. Davis et al. (1966) studied the terminal phalanx, Meema et al. (1965) the proximal radius, and Nordin et al. (1968) the third lumbar vertebra. The third metacarpal was used as our skeletal reference site since the reproducibility of $\pm 4 \%$ which we obtained is relatively good in terms of skeletal mensuration in vivo (Shimmins et al., 1972 b). We have also established that metacarpal ash per unit length in women correlates well with the bone density of the radius, femur, and spine in vitro (Aitken et al., $1973 \mathrm{c}$ ), and hence it would be reasonable to assume that the changes in metacarpal mineral which we found in this study were representative of the skeleton as a whole.

The way in which oestrogens produce their osteotrophic action is far from clear. It has been suggested that oestrogens prevent postmenopausal osteoporosis by antagonizing the effect of parathyroid hormone on bone (Heaney, 1965; Jasani et al., 1965; Nordin, 1971). This hypothesis has been used to explain the characteristic fall in urinary calcium excretion and the lowering of the serum calcium concentration observed in patients treated with oestrogens (Young et al., 1968). This hypothesis, however, clearly ignores the hypophosphataemic and hyperphosphaturic effects of such therapy (Nassim et al., 1956; Aitken et al., 1971), which are more in keeping with an increase in parathyroid activity, and also makes no allowance for the haemodilution and hypoproteinaemia which are seen in association with oestrogen administration (Preedy and Aitken, 1956; Pilgeram and Pickart, 1963; Robertson, 1967; Aitken et al., 1973 b) and which would be attended by an obligatory fall in the serum calcium concentration (Dent, 1962). Furthermore, Kurihara and Shibata (1966) showed that oestrogens were effective osteotrophic agents in the absence of intact parathyroid function. In the present study the hypocalcaemic, hypocalciuric, hypophosphataemic, and hyperphosphaturic effects of oestrogen therapy were quite unrelated to the osteotrophic response observed, and it is clear that other factors will have to be considered in order to explain the variable response to oestrogen therapy which we found.

The possible skeletal benefits of prolonged low-dose oestrogen therapy must, however, be assessed in relation to the long-term safety of such measures. Gow and MacGillivray (1971), in an uncontrolled study of mestranol therapy in 24 postmenopausal Aberdonian women, described a $15 \%$ incidence of venous thromboembolism within four months of starting treatment. Our findings do not support their pessimistic views about the administration of mestranol after the menopause. The largescale controlled prospective studies of Drill and Calhoun (1968) and Drill (1972) in the U.S.A. have also failed to show a significant thrombogenic effect of oestrogen-containing oral contraceptives. The three other vascular episodes found in the mestranol group should not, however, be ignored, but it is not certain to what extent mestranol contributed to these events. Both the woman who died of the cerebrovascular catastrophe and the woman who sustained the transient hemiparesis were overtly hypertensive before mestranol was prescribed. The presence of established hypertension should perhaps make 
one wary of prescribing oestrogens, since a small increase in blood pressure has been observed in women taking the contraceptive pill (Weir et al., 1971). We have not observed any significant change in either systolic or diastolic blood pressure after mestranol therapy, but a small increase might have been obscured in this study because of interobserver errors and the use of a variety of sphygmomanometers. Both the woman who had the transient hemiparesis and the woman with tachycardia and chest pain made complete recoveries while continuing mestranol.

Disordered hepatic function was not seen more commonly in the mestranol-treated women than in the controls in this study, whereas Eisalo et al. $(1964,1968)$ reported that abnormalities of liver function were not infrequently seen in Finnish women taking the contraceptive pill and that in this respect mestranol was more hepatotoxic than other oestrogens. These workers, however, made their measurements within a few weeks of starting treatment, whereas none of our measurements were made earlier than six months after starting mestranol. Our findings are more in keeping with those of Swaab (1964) and Swyer (1966). Transient alterations in hepatic function at the start of oestrogen therapy are not in themselves a contraindication to such treatment, since our concern should be more with the long-term safety of these drugs. This consideration is also important in interpreting the disordered carbohydrate metabolism which is found within a few months in $50 \%$ of women given mestranol-containing oral contraceptives ( $\mathrm{Di}$ Paola et al., 1968) because this abnormality characteristically disappears spontaneously within 18 months of continued treatment (Di Paola et al., 1970). The mean fasting blood sugar concentration in the mestranol-treated women an average of 18 months after starting therapy was significantly lower than that found in the controls. The single case of frank diabetes mellitus which we found would, in view of the patient's family and past medical history, have been very likely to develop diabetes mellitus whether she had been given mestranol or not.

Low-dose mestranol therapy appears to be effective in the prevention and early treatment of postmenopausal osteoporosis provided that treatment is started within three years of the menopause. There does not, however, appear to be any justification for prescribing such treatment when six or more years have elapsed since the cessation of ovarian function. These results should not be interpreted as signifying that postmenopausal osteoporosis is the result of oestrogen deficiency, and the importance of the lack of other substances of ovarian origin, and the progestogens in particular, in the aetiology of postmenopausal osteoporosis should not be ignored (Aitken et al., 1972). The prolonged administration of mestranol appeared to be reasonably safe, but the total period of observation was too short to make meaningful claims, since such prophylactic treatment, once embarked on, would probably have to be continued for many years. Furthermore, we cannot justify the extrapolation of these results to women with intact uteri, since in that instance treatment would probably have to be intermittent in order to ensure regular shedding of the endometrium. It is hoped that when the mode of action of the in-vivo osteotrophic properties of oestrogens have been elucidated it may be possible to make a more scientific approach towards the rational treatment of postmenopausal osteoporosis.

This work was supported by grants from the Scottish Hospital Endowments Research Trust, the National Fund for Research into
Crippling Diseases, and G. D. Searle and Co. Ltd., High Wycombe, who also provided the mestranol and placebo tablets. We are also indebted to the staff of the hospital pharmacy for dispensing the tablets; to Drs. E. L. Murray, D. McKay Hart, sen., A. Davidson, and D. A. Smith for clinical help; to Dr. P. W. Horton and Messrs. J. B. Anderson and C. B. Smith for technical help; and to the consultant gynaecologists at the Western Infirmary and Stobhill Hospital for allowing us to contact their patients.

\section{References}

Aitken, J. M., and Lindsay, R. (1972). Fournal of Physiology, 226, 93P. Aitken, J. M., Hart, D. McKay, and Smith, D. A. (1971). Clinical Science, 41, 233.

Aitken, J. M., Armstrong, E., and Anderson, J. B. (1972). Fournal of Endocrinology, 55, 79.

Aitken, J. M., et al. (1973 a). British Medical fournal, 2, 325.

Aitken, J. M., Lindsay, R., and Hart, D. McKay (1973 b). Clinical Science, 44, 91.

Aitken, J. M., et al. (1973 c). Fournal of Bone and foint Surgery (B). In press. Albright, F. (1947). Recent Progress in Hormone Research, 1, 293.

Albright, F., Smith, P. H., and Richardson, A. M. (1941). Fournal of the American Medical Association, 116, 2465.

Anderson, I. A. (1950). Quarterly fournal of Medicine, 19, 67.

Anderson, J. B., Shimmins, J., and Smith, D. A. (1966). British fournal of Radiology, $39,443$.

Davis, M. E., Strandjord, N. M., and Lanzl, L. H. (1966). Fournal of the American Medical Association, 196, 219.

Dent, C. E. (1962). British Medical . Fournal, 2, 1419.

Di Paola, G., Puchulu, F., Robin, M., Nicholson, R., and Marti, M. (1968). American fournal of Obstetrics and Gynecology, 101, 206.

Di Paola, G., Robin, M., and Nicholson, R. (1970). American fournal of Obstetrics and Gynecology, 107, 124 .

Drill, V. A. (1972). . Fournal of the American Medical Association, 219, 583.

Drill, V. A. (1972). Fournal of the American Medical Association, 219, 583.
Drill, v. A., and Calhoun, D. W. (1968). Fournal of the American Medical

Association, 206, 77.
Eisalo, A., Järvinen, P. A., and Luukkainen, T. (1964). British Medical

Eisalo, A., Heino, A., and Räsänen, V. (1968). Acta Obstetricia et Gynecologica Scandinavica, 47, 58.

Gow, S., and MacGillivray, I. (1971). British Medical fournal, 2, 73.

Heaney, R. P. (1965). American fournal of Medicine, 39, 877.

Henneman, P. H., and Wallach, S. (1957). Archives of Internal Medicine 100,715 .

Jasani, C., Nordin, B. E. C., Smith, D. A., and Swanson, I. (1965). Proceedings of the Royal Society of Medicine, 58, 441 .

Kurihara, Y., and Shibata, K. (1966). Gunma fournal of Medical Sciences,

Lafferty, F. W., Spencer, G. E., and Pearson, O. H. (1964). American fournal of Medicine, 36,514 .

Meema, H. E., Bunker, M. L., and Meema, S. (1965). Obstetrics and Gyne-

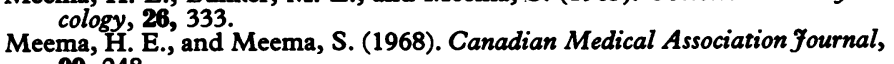

99, 248.
Nassim, J. R., Saville, P. D., and Mulligan, L. (1956). Clinical Science, 15, 367.

Nordin, B. E. C. (1971). British Medical Fournal, 1, 571.

Nordin, B. E. C., and Bulusu, L. (1968). Postgraduate Medical fournal, 44, 93 . Nordin, B. E. C. Hodgkinson, A., and Peacock, M. (1967). Clinical Ortho-
paedics and Related Research, 52, 293.

Nordin, B. E. C., Young, M. M., Bentley, B., Ormondroyd, P., and Sykes, J. (1968). Clinical Radiology, 19, 459.

Pilgeram, L. O., and Pickart, L. R. (1963). Proceedings of the Society for Experimental Biology and Medicine, 112, 758.

Preedy, J. R. K., and Aitken, E. H. (1956). Fournal of Clinical Investigation,

35, 423. Jowsey, J., Kelly, P. J., Jones, J. D., and Maher, F. T. (1969).
Rigg, B. L., fournal of Clinical Investigation, 48, 1065.

Robertson, G. S. (1967). Lancet, 1, 232. Shimmins, J., Smith, D. A., Aitken, M., Anderson, J. B., and Gillespie,
F. C. (1972 a). Clinical Radiology, 23, 47. F. C. (1972 a). Clinical Radiology, 23, 47 .
Shimmins, J., Anderson, J. B., Smith, D. A., and Aitken, M. (1972 b). Clinical Radiology, 23, 42.

Swaab, L. I. (1964). British Medical fournal, $2,755$.

Swyer, G. I. M. (1966). Current Medicine and Drugs, 6, No. 9, p. 17.

Trudeau, D. L., and Freier, E. F. (1967). Clinical Chemistry, 13, 101.

Weir, R. J., et al. (1971). Lancet, i, 467.

Wroblewski, F., and LaDue, J. S. (1955). Proceedings of the Society for Experimental Biology and Medicine, 90, 210.

Young, M. M., Jasani, C., Smith, D. A., and Nordin, B. E. C. (1968.) Clinical Science, 34, 411. 